\title{
Chronic Hypoxia Enhances Expression and Activity of Mitochondrial Creatine Kinase and Hexokinase in the Rat Ventricular Myocardium
}

\author{
Petra Waskova-Arnostova ${ }^{a}$ Dita Kasparova ${ }^{a}$ Barbara Elsnicova ${ }^{a} \quad$ Jiri Novotny ${ }^{a}$ \\ Jan Neckar ${ }^{b}$ Frantisek Kolar ${ }^{b}$ Jitka Zurmanova ${ }^{a}$ \\ aDepartment of Physiology, Faculty of Science, Charles University in Prague, 'DInstitute of Physiology, \\ Academy of Sciences of the Czech Republic, Prague, Czech Republic
}

\section{Key Words}

Creatine kinase - Hexokinase - Normobaric hypoxia - Left ventricle Right ventricle • Mitochondria co-localization

\begin{abstract}
Background: Creatine kinase (CK) and hexokinase (HK) play a key role in myocardial energy homeostasis. We aimed to determine CK and HK expression and enzyme activity in the left (LV) and right (RV) ventricles of rats adapted for 3 weeks to normobaric hypoxia $\left(10 \% \mathrm{O}_{2}\right)$ either continuously $(\mathrm{CNH})$ or intermittently with 1 -h or $16-\mathrm{h}$ normoxic episode per day. Methods: The Real-Time RT-PCR, Western blot, and enzyme-coupled assays were used. In addition, the effect of $\mathrm{CNH}$ on the HK co-localization with mitochondria, which can inhibit apoptosis, was assessed using immunofluorescence techniques. Results: CK and HK activities increased in the LV during all hypoxic adaptations, which was consistent with elevated protein levels of mitochondrial mtCKs, cytosolic CKB, HK1, and HK2 isoforms. Enzyme activities also increased in the hypoxic RV, but only CKB protein was elevated. No effect of CNH on HK1 or HK2 COlocalization with mitochondria was observed. Conclusion: Up-regulation of $\mathrm{mtCKs}$ and HK isoforms may stimulate the respiratory chain and help to maintain energy homeostasis of chronically hypoxic myocardium and prevent oxidative stress. In this way, CK and HK enzymes can possibly participate in the establishment of ischemia-resistant phenotype of chronically hypoxic hearts.
\end{abstract}




\section{Cellular Physiology and Biochemistry}

Cell Physiol Biochem 2014;33:310-320

DOI: $10.1159 / 000356671$

Published onlıne: January 31, 2014

C) 2014 S. Karger AG, Basel

www.karger.com/cpb

Waskova-Arnostova et al.: Mitochondrial CK and HK in Hypoxic Heart

\section{Introduction}

High energy demand of mammalian heart is critically dependent on continuous and adequate production of ATP by oxidative phosphorylation. Efficiency of energy transfer between the sites of energy production and utilization primarily depends on the creatine kinase (CK) system, which functions in cardiac muscle cells as the main energy buffer keeping a high ATP/ADP ratio and optimal pH simultaneously [1-4]. It catalyzes a reversible reaction of creatine with ATP in which creatine is phosphorylated [5].

Cardiomyocytes express three CK isoforms: two cytosolic (CKM, CKB) and one mitochondrial sarcomeric (mtCKs). The major cytosolic CK isoform CKM associates with subcellular structures in close proximity to ATPases $[6,7]$ and regenerates ATP according to actual energy requirements. CKM also maintains the phosphocreatine ( $\mathrm{PCr}$ ) pool by coupling with the glycolytic system, where it preferably transphosphorylates the produced ATP $[1,8]$. The minor cytosolic isoform CKB is predominantly expressed in early developmental stages of the heart. In adulthood it functions only as a constitutive enzyme, which is overexpressed under conditions of metabolic challenge, such as hypertrophy $[9,10]$, hypertension $[9,11$, $12]$ and hypoxia $[13,14]$. In contrast to CKM, CKB occurs in cytosol only as a solubilized molecule unable to bind with intracellular structures [15]. The mitochondrial sarcomeric isoform mtCKs located in the intermembrane space $[16,17]$ plays an important role during "physiological" hypoxia. The mtCKs supports oxidative phosphorylation by increasing availability of ADP for complex $V$ of the respiratory chain $[18,19]$ and thus regulates the membrane potential and controls formation of reactive oxygen species (ROS) [20]. It also prevents opening of the mitochondrial permeability transition pore (MPTP), a well known trigger of apoptotic cell death [20-24].

Importantly, apoptosis is also controlled by one of the key glycolytic enzymes, hexokinase (HK) [25-29] via its interaction with outer mitochondrial membrane. The HK association with voltage-dependent anion channel (VDAC) facilitates ADP flux into mitochondria and thus supports oxidative phosphorylation [30], which prevents ROS overproduction [31], similarly as mtCKs does. There are two HK isoforms expressed in cardiomyocytes, HK1 and HK2 $[32,33]$. Under normoxic conditions, HK1 binds to the outer mitochondrial membrane $[34,35]$, whereas HK2 is mainly soluble [32, 36]. Ischemia increases binding of HK2 to the outer mitochondrial membrane resulting in enhancement of oxidative phosphorylation [37].

Any perturbation of oxygen supply to the heart results in physiological or pathophysiological changes depending on the degree, duration, and periodicity of the hypoxic insult. While severe oxygen deprivation may cause myocardial injury and ultimately heart failure, adaptation to moderate chronic hypoxia leads to complex adaptive changes [38] including metabolic remodeling due to ROS-sensitive induction of a fetal gene program that restores the balance between energy supply and demand [39]. Several studies reported rather diverse and inconclusive results regarding the effects of chronic hypoxia on myocardial energy transfer system $[13,14,40]$, which likely reflects differences in hypoxic challenge and animal species. It is unknown whether continuous and intermittent hypoxias have a different impact on CK and HK activities and isoform profiles, especially in the light of our recent studies, which showed that the cardiac ischemic tolerance of chronically hypoxic hearts is strictly dependent on hypoxic model and regimen. We showed that continuous hypoxia as well as intermittent hypoxia lasting $8 \mathrm{~h}$ per day increases cardiac tolerance to ischemic injury, but the regimen based on $23 \mathrm{~h}$ of hypoxia per day interrupted with only 1-h normoxic episode does not induce a cardioprotective phenotype [41, 42]. Therefore, the aim of the present study was to determine the expression of CK and HK isoforms and the activity of these enzymes in ventricular myocardium of rats adapted to three different regimens of chronic normobaric hypoxia. In view of an increased workload imposed by chronic hypoxia on the RV as a consequence of pulmonary hypertension, the hypertrophied RV and nonhypertrophied LV were examined separately. 


\section{Cellular Physiology and Biochemistry}

Cell Physiol Biochem 2014;33:310-320

\begin{tabular}{l|l}
\hline DOI: $10.1159 / 000356671$ & (C) 2014 S. Karger AG, Basel
\end{tabular}

Published onlıne: January 31, $2014 \quad$ www.karger.com/cpb

Waskova-Arnostova et al.: Mitochondrial CK and HK in Hypoxic Heart

\section{Materials and Methods}

Animal model

Adult male Wistar rats obtained from a breeding company (Velaz, Ltd., Czech Republic) were exposed for 3 weeks to normobaric hypoxia $\left(10 \% \mathrm{O}_{2}\right)$ under the following three regimens: continuous hypoxia for $24 \mathrm{~h} /$ day (CNH), intermittent hypoxia for $23 \mathrm{~h}$ /day with a single 1-h normoxic period per day (INH-23) or intermittent hypoxia for $8 \mathrm{~h}$ /day with a single 16-h normoxic period per day (INH-8). A control group (N) was kept under normoxic conditions for the same period of time. Rats were fed a standard laboratory diet and kept at the 12/12-h light/dark cycle. The maintenance and handling of experimental animals was in accordance with the Guide for the Care and Use of Laboratory Animals published by the US National Institutes of Health (NIH Publication No. 85-23, revised 1996). The experimental protocol was approved by the Animal Care and Use Committee of the Institute of Physiology, Academy of Sciences of the Czech Republic.

\section{Tissue preparation}

All rats were killed by decapitation. Hearts were rapidly excised and washed in ice-cold saline solution. The LV and RV were dissected, immediately frozen in liquid nitrogen and weighed. The frozen tissue was pulverized in liquid nitrogen and subsequently homogenized either in homogenization buffer $(12.5 \mathrm{mM}$ Trizma base-TRIS, $2.5 \mathrm{mM}$ EGTA, $1 \mathrm{mM}$ EDTA, $250 \mathrm{mM}$ sucrose, $5 \mathrm{mM}$ DTT, and protease inhibitor cocktail (Complete, Roche Diagnostics), pH 7.4) for Western blot (WB) and enzyme activities or in Trizol Reagent (Invitrogen) for isolation of mRNA. The homogenates for WB and enzyme activities were aliquoted and stored at $-80^{\circ} \mathrm{C}$. Protein concentration was measured using the Bradford dye binding assay (Sigma Aldrich).

\section{Real-Time RT-PCR analysis}

All procedures including isolation of total mRNA, following reverse transcription as well as PCR quantification were described previously in details [43]. Real-Time RT-PCR analyses were performed according to manufacture instructions by Light Cycler Roche using Light Cycler 480 Probes Master and the following specific primers together with Mono-Color Hydrolysis Probes (\#) designed by the Universal Probe Library Assay Design Center (UPL, Roche Applied Science): HK1_F: tctgggcttcaccttctcat, HK1_R: atcaagattccacagtccaggt and \#121; HK2_F: ccagcagaacagcctagacc, HK2_R: agatgccttgaatccctttg and \#101; CKM_F: ccgcagcatcaagggtta, CKM_R: cccgtcaggctgttgaga and \#16;CKB_F: ccacttcctcttcgacaagc, CKB_R: ggaacgtcttattgtcattgtgc and \#84; mtCKs_F: gccaccccttcattaagactg, mtCKs_R: caaaaaggtcagcaaacacct and \#83; HPRT_F: gaccggttctgtcatgtcg, HPRT_R: acctggttcatcatcactaatcac and \#95.

\section{SDS-PAGE and WB analysis}

All steps of protein expression analysis were performed essentially as described previously [43]. Samples from each experimental group and from both ventricles were always run on the same gel and quantified on the same membrane. The analysis of each membrane was repeated four times for each antibody and the results normalized to the total protein. The total protein concentration was used as the most suitable referential value [44]. Quantitative data obtained from 5 animals in each experimental group are presented as a percentage of total values. In this study we used the following primary polyclonal antibodies: goat anti-mtCKs (sc-15168), goat anti-CKM (sc-15164), goat anti-CKB (sc-15157), rabbit anti-HK1 (sc-28885), and rabbit anti-HK2 (sc-28889) (Santa Cruz Biotechnology). Appropriate anti-goat or anti-rabbit secondary antibodies conjugated to horseradish peroxidase were obtained from Santa Cruz Biotechnology and GE Healthcare Amersham, respectively.

\section{Enzyme activity}

Specific enzyme activities of CK and HK were assessed by enzyme-coupled assays and determined by measurement of absorbance at $339 \mathrm{~nm}$ in 96-well plates using a multireader Synergy ${ }^{\mathrm{TM}}$ HT (Biotek Instruments). The HK activity was measured according to a slightly modified Worthington protocol (http:// www.worthington-biochem.com/HK/; Worthington Biochemical Corporation). The assay buffer consisted of $0.05 \mathrm{M}$ TRIS, $13.3 \mathrm{mM} \mathrm{MgCl}_{2}$, $0.8 \mathrm{mM}$ NAD, $0.8 \mathrm{mM} \mathrm{ATP,} 0.5 \%$ Triton X-100, and $1 \mathrm{U} / \mathrm{ml}$ G-6-P dehydrogenase ( $\mathrm{pH}$ 8.0). Samples (60 $\mu \mathrm{g}$ per well) in $167 \mu \mathrm{l}$ of the HK assay buffer were placed into 96-well plates. The reaction was initiated after $2 \mathrm{~min}$ by the addition of $33 \mu \mathrm{l}$ of starting solution (1.5 $\mathrm{M}$ glucose in TRIS- $\mathrm{MgCl}_{2}$ 
Cellular Physiology
and Biochemistry

Cell Physiol Biochem 2014;33:310-320

DOI: $10.1159 / 000356671$

Published onlıne: January 31, 2014

Waskova-Arnostova et al: Mitochondrial CK and HK in Hypoxic Heart

Table 1. Body Weight, Relative Ventricular and Septum Weights, Heart Weight and Hematocrit in Rats Adapted to Continuous and Intermittent Hypoxia and in Normoxic Controls. CNH, continuous hypoxia; INH-23, intermittent hypoxia for $23 \mathrm{~h}$ /day; INH-8, intermittent hypoxia for $8 \mathrm{~h} /$ day; BW, body weight; RV, weight of the right ventricle (RV); LV, weight of the left ventricle (LV); S, weight of the septum; RV/BW, relative weight of the RV; LV/BW, relative weight of the LV; HW/BW, relative weight of the heart. Values are mean \pm S.E.M. $(n=5) .{ }^{*} P<0.05$ vs. normoxia; ${ }^{\dagger} P<0.05$ vs. INH8

\begin{tabular}{lcccccccc}
\hline Group & $\begin{array}{c}\text { BW } \\
(\mathrm{g})\end{array}$ & $\begin{array}{c}\mathrm{RV} \\
(\mathrm{mg})\end{array}$ & $\begin{array}{c}\mathrm{LV} \\
(\mathrm{mg})\end{array}$ & $\begin{array}{c}\mathrm{S} \\
(\mathrm{mg})\end{array}$ & $\begin{array}{c}\mathrm{RV} / \mathrm{BW} \\
(\mathrm{mg} / \mathrm{g})\end{array}$ & $\begin{array}{c}\text { LV/BW } \\
(\mathrm{mg} / \mathrm{g})\end{array}$ & $\begin{array}{c}\text { HW/BW } \\
(\mathrm{mg} / \mathrm{g})\end{array}$ & $\begin{array}{c}\text { Hematocrit } \\
(\%)\end{array}$ \\
\hline Normoxia & $361 \pm 9$ & $189 \pm 5$ & $460 \pm 14$ & $201 \pm 6$ & $0.52 \pm 0.01$ & $1.28 \pm 0.04$ & $2.36 \pm 0.05$ & $42.9 \pm 0.9$ \\
INH8 & $347 \pm 5$ & $224 \pm 6^{*}$ & $472 \pm 9$ & $194 \pm 3$ & $0.65 \pm 0.02^{*}$ & $1.36 \pm 0.03$ & $2.57 \pm 0.06$ & $54.2 \pm 1.3^{*}$ \\
INH23 & $308 \pm 8^{*+}$ & $319 \pm 16^{*+}$ & $453 \pm 21$ & $178 \pm 10$ & $1.03 \pm 0.04^{*+}$ & $1.47 \pm 0.05$ & $3.08 \pm 0.10^{*+}$ & $58.5 \pm 1.7^{*+}$ \\
CNH & $311 \pm 7^{*+}$ & $351 \pm 28^{*+}$ & $451 \pm 26$ & $189 \pm 12$ & $1.12 \pm 0.07^{*+}$ & $1.45 \pm 0.08$ & $3.18 \pm 0.15^{*+}$ & $61.5 \pm 1.5^{*+}$ \\
\hline
\end{tabular}

buffer, $\mathrm{pH}$ 8.0) and the assay was run at $30^{\circ} \mathrm{C}$ for $15 \mathrm{~min}$. The $\mathrm{CK}$ activity was measured at $37^{\circ} \mathrm{C}$ for $10 \mathrm{~min}$ using a commercial kit (CK NAC liq. SYS 1, Roche Diagnostics). Specific enzyme CK and HK activities were expressed as units per gram protein (U/g) [45].

\section{Immunofluorescence analysis}

The subcellular localization of HK1 and HK2 and their co-localization with the mitochondrial membrane were investigated in the LV and RV of normoxic and CNH rats as the shift of Pearson's correlation coefficient. Primary polyclonal antibodies from Santa Cruz Biotechnology (HK1 sc-28885, HK2 sc-28889) or from Abcam (HK1 ab78420, HK2 ab78259) were used. Quantitative correlation analysis was calculated in the whole scanned area. Appropriate sampling density, precise background subtraction, and correctly processed deconvolution along with Replicate-Based Noise Corrected Correlation (RBNCC) method enabled us to reliably assess signal co-localization. All detailed steps of immunofluorescence staining, fluorescence microscopy, and quantification were performed as described previously [43].

\section{Statistical analysis}

Five hearts from each experimental group were analyzed. Data are expressed as mean \pm SEM. Statistical evaluation was performed using One-way ANOVA followed by a post hoc Dunett's multiple comparison test or Mann Whitney test (GraphPad Prism 5.00 software). Values of $P<0.05$ were considered statistically significant.

\section{Results}

As shown in Table 1, adaptation of rats to INH-23 and CNH led to growth retardation by about $14 \%$ as compared to normoxic controls. INH-8 had no significant effect on the body weight. While chronic hypoxia did not significantly affect the LV weight, it resulted in the RV hypertrophy, which was more pronounced in the CNH and INH-23 groups than in the INH-8 group. Similarly, the increase of hematocrit was proportional to the duration of daily hypoxic exposure.

Adaptation to all hypoxic regimens affected neither mRNA nor protein levels of CKM in both ventricles, except for a slight decrease of the LV transcript in the INH-23 group (Fig. $1 \mathrm{~A}, \mathrm{~B}$ ). On the other hand, chronic hypoxia up-regulated CKB at mRNA and protein levels in both LV and RV, although only some groups exhibited statistically significant difference from normoxic controls due to rather high variability in this isoform level (Fig. 1C, D). The protein expression of mtCKs was significantly increased in the LV after the adaptation to all hypoxic regimens (by $33 \%, 29 \%$, and $30 \%$ in $\mathrm{CNH}$, INH-23, and INH-8 groups, respectively), while the LV levels of mtCKs mRNA increased only in $\mathrm{CNH}$ and INH-8 groups. In contrast, no effect of hypoxia on mtCKs expression was observed in the RV (Fig. 1E, F).

Protein and mRNA levels of both HK isoforms were markedly higher in the normoxic RV than in the LV, which is in line with our previous findings [43]. All hypoxic regimens similarly 


\section{Cellular Physiology and Biochemistry}

Cell Physiol Biochem 2014;33:310-320 DOI: $10.1159 / 000356671$

Published online: January 31, 2014

Waskova-Arnostova et al.: Mitochondrial CK and HK in Hypoxic Heart

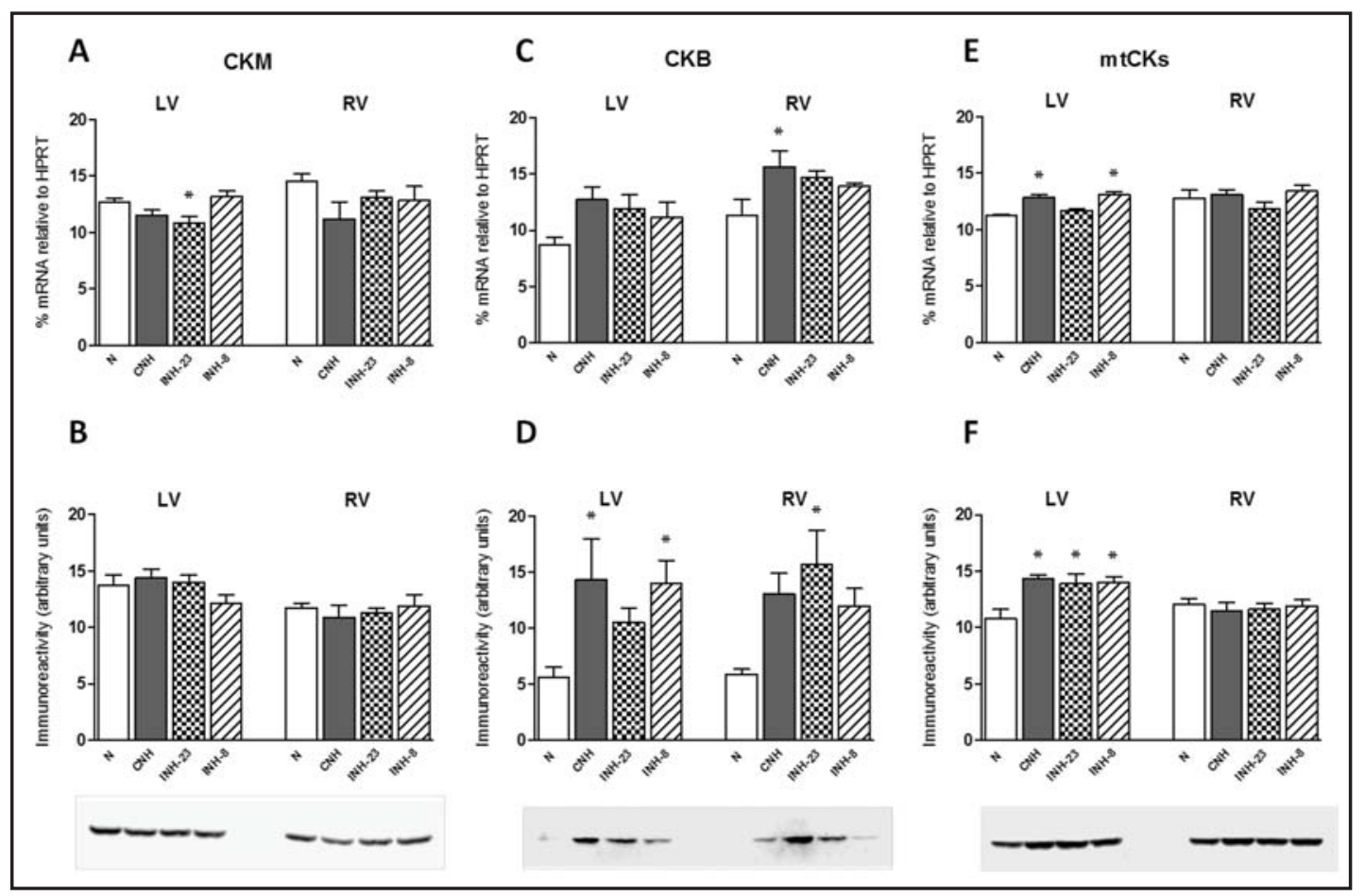

Fig. 1. Expression of CK isoforms in the left (LV) and right (RV) ventricles. The relative levels of CKM mRNA (A), CKM protein (B), CKB mRNA (C), and CKB protein (D), mtCKs mRNA (E) and mtCKs protein (F) are expressed as a percentage of total amount determined in myocardial $\mathrm{LV}$ and RV preparations from normoxic rats $(\mathrm{N})$, from rats adapted to continuous hypoxia (CNH), intermittent hypoxia for $23 \mathrm{~h} /$ day (INH-23), and intermittent hypoxia for $8 \mathrm{~h} /$ day (INH-8). Values are mean \pm S.E.M. $(n=5) .{ }^{*} P<0.05 v s$. N.

Fig. 2. Expression of HK1 and HK2 isoforms in the left (LV) and right (RV) ventricles. The relative levels of HK1 mRNA (A), HK1 protein (B), HK2 mRNA (C), HK2 protein (D) are expressed as a percentage of total amount determined in myocardial LV and RV preparations from normoxic rats $(\mathrm{N})$, from rats adapted to continuous hypoxia (CNH), intermittent hypoxia for 23 h/day (INH-23), and intermittent hypoxia for $8 \mathrm{~h} /$ day (INH-8). Values are mean \pm S.E.M. $(n=5) .{ }^{*} P<0.05$ vs. N; \# $P<0.05$ vs. corresponding LV.

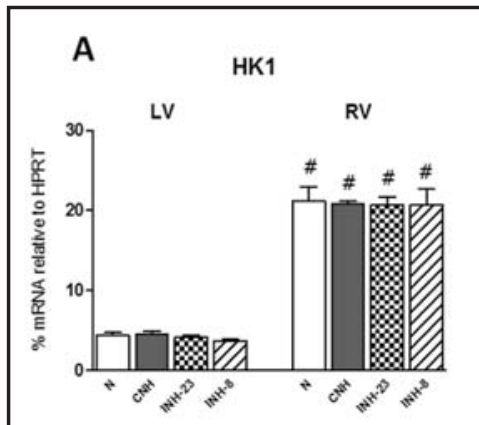

B

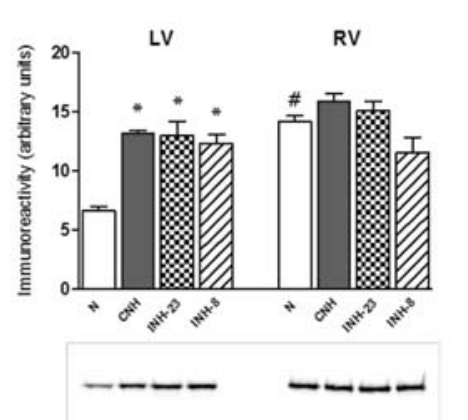

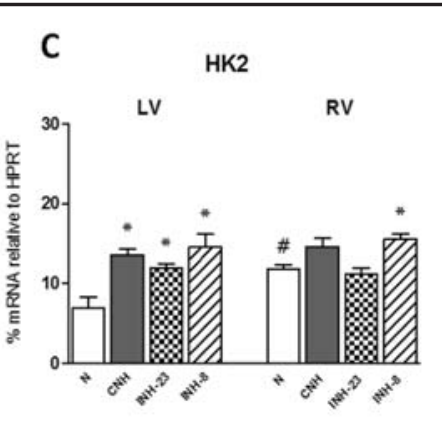

D

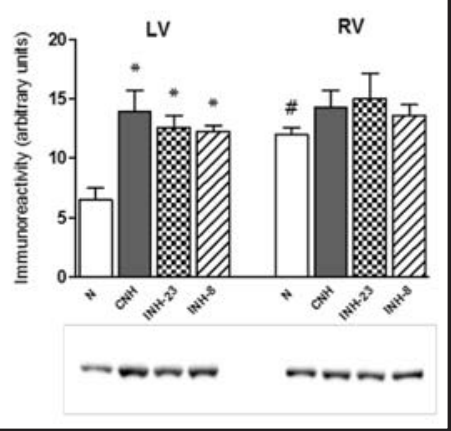

increased HK1 protein levels in the LV (by $99 \%$, $95 \%$, and $86 \%$ in CNH, INH-23, and INH8 groups, respectively), but did not affect HK1 mRNA levels. Interestingly, adaptation to hypoxia affected neither mRNA nor protein levels of HK1 in the RV (Fig. 2A, B). All regimens 


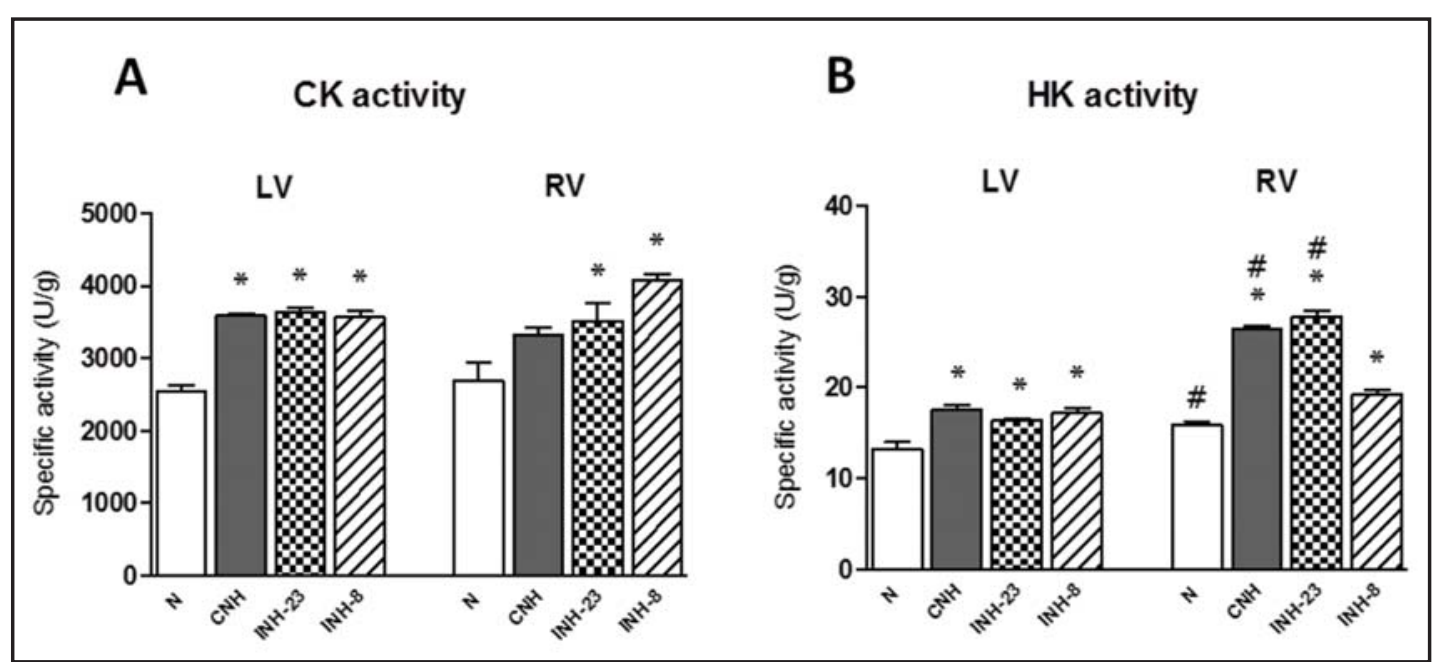

Fig. 3. Specific enzyme activities of CK and HK in the left (LV) and right (RV) ventricles. CK (A) and HK (B) activity are expressed as units per gram protein $(\mathrm{U} / \mathrm{g})$ in myocardial $\mathrm{LV}$ and $\mathrm{RV}$ preparations from normoxic rats $(\mathrm{N})$, from rats adapted to continuous hypoxia (CNH), intermittent hypoxia for $23 \mathrm{~h} /$ day (INH-23), and intermittent hypoxia for $8 \mathrm{~h}$ /day (INH-8). Values are mean \pm S.E.M. $(n=5){ }^{*} P<0.05$ vs. N; $\# P<0.05$ vs. corresponding LV.

of hypoxia up-regulated both mRNA (by 74-112\%) and protein (by 94-113\%) level of HK2 in the $\mathrm{LV}$. In the RV, the protein expression of HK2 remained unchanged and mRNA level increased only in the INH-8 group (Fig. 2C, D).

Adaptation to hypoxia markedly increased CK activity in the LV by $41 \%$ (CNH), $43 \%$ (INH-23), and $40 \%$ (INH-8), which was in agreement with the enhanced expression of mtCKs and CKB proteins. In the RV, only adaptations to INH-23 and INH-8 significantly increased CK activity by $31 \%$ and $51 \%$, respectively (Fig. 3A). All hypoxic regimens also significantly increased $\mathrm{HK}$ activity in the LV by $32 \%$ (CNH), $23 \%$ (INH-23), and $29 \%$ (INH-8), which was in line with the up-regulation of HK1 and HK2 protein levels. The HK activity in the RV was higher than in the LV already under normoxic conditions and chronic hypoxia resulted in further increases by $67 \%$ (CNH), $75 \%$ (INH-23), and $21 \%$ (INH-8) (Fig. 3B).

The fluorescence analysis showed a higher co-localization of HK1 with mitochondria than HK2 in the normoxic LV and RV, which is in accordance with our previous study [43]. In addition, a higher co-localization of HK1 with mitochondria, compared to HK2, was also observed in the $\mathrm{RV}$ of $\mathrm{CNH}$ rats. However, adaptation to $\mathrm{CNH}$ did not affect the mitochondrial co-localization of both isoforms in the $\mathrm{LV}$ as well as in the RV, compared to the normoxic controls (Fig. 4A, B). Sufficient sensitivity of quantitative immunofluorescence technique was verified in pilot experiments on isolated rat hearts exposed to 30-min global no-flow ischemia. Compared to non-ischemic controls, co-localization of HK2 with mitochondria was substantially increased in as indicated by the Pearson's correlation coefficient: 0.61 for control and 0.68 for ischemic hearts.

\section{Discussion}

The present study demonstrated that adaptation of rats to different regimens of chronic normobaric hypoxia significantly increased the total CK activity in the LV, which is in accordance with an increased expression of mtCKs and CKB isoforms. In view of the fact, that CKB represents a minor isoform in the mature heart, we can assume that the increase of total CK activity under hypoxic conditions can be attributed mainly to mtCKs. This suggests that up-regulation of mtCKs and increase of its activity induced by chronic hypoxia may represent a compensatory mechanism engaged in improving oxidative energy metabolism. 


\section{Cellular Physiology and Biochemistry}

Cell Physiol Biochem 2014;33:310-320

DOI: $10.1159 / 000356671$

ublished online: January 31, 2014

Waskova-Arnostova et al.: Mitochondrial CK and HK in Hypoxic Heart

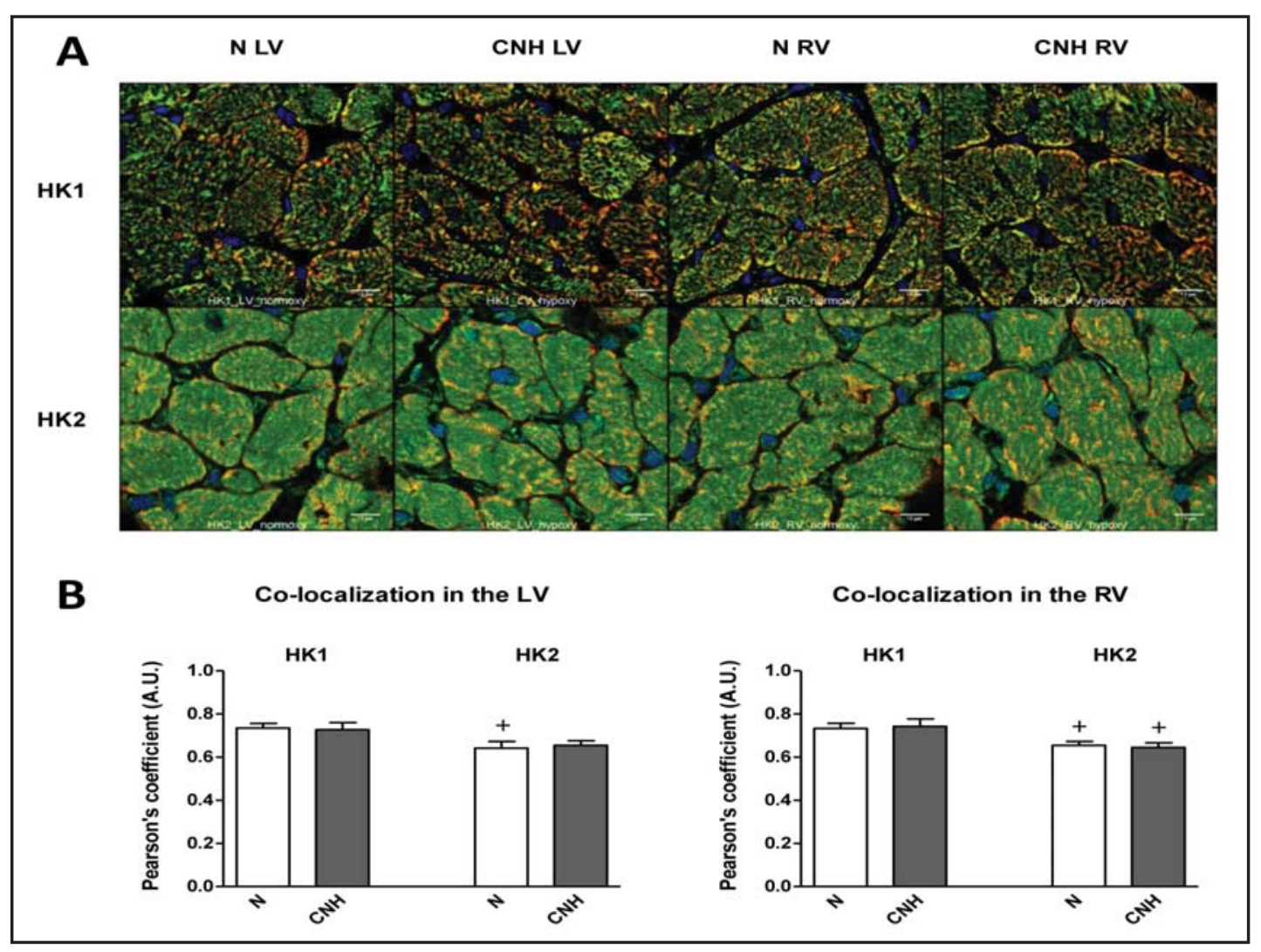

Fig. 4. Representative qualitative images of transversal cross cryosections showing the co-localization of HK1 and HK2 with mitochondria in the myocardial left (LV) and right (RV) ventricles from normoxic rats $(\mathrm{N})$ and from rats adapted to continuous hypoxia $(\mathrm{CNH})(\mathrm{A})$. The green color represents specific HK1 or HK2 staining and blue color indicates the nuclear 4',6-diamidino-2-phenylindole (DAPI) staining. Red color represents the distribution of the mitochondrial compartments (I-V complexes). The increase in yelloworange color indicates an increased co-localization of HK1 and HK2 with mitochondria expressed as the Pearson's correlation coefficients (B). Values are mean \pm S.E.M. $(n=5) .+P<0.05$ vs. corresponding HK1.

Adaptation to hypoxia leads to mitochondrial biogenesis manifested by the increased number and decreased size of mitochondria [46]. This process is regulated by mitochondrial transcription factor A (TFAM) under conditions of impaired mitochondrial energy supply [47]. It can be assumed, that TFAM also plays a role in transcriptional regulation of mtCKs leading to stimulation of oxidative phosphorylation $[18,19]$. The up-regulation of CKB points to the activation of fetal gene expression program, which is in line with the abundant evidence of hypoxia-induced metabolic changes resembling early developmental stages [39]. The increased expression of CKB together with the elevated total CK activity was observed also in the RV, where mtCKs expression remained unchanged. This may imply that the increase of total CK activity is at least partially related to the phosphorylation of CKB mediated, for example, by protein kinase C (PKC), which leads to increased CKB activity [48, 49] and affinity for PCr [50]. Apparently, phosphorylated CKB is able to provide a higher ATP supply for energy-requiring processes at low $\mathrm{PCr}$ levels [49], which may be likely required also during hypoxia. Our results showed a discordant trend in the expression between two major isoforms mtCKs and CKM in the LV of all hypoxic groups, suggesting different regulatory mechanisms controlling the expression of these genes during hypoxia, although it is known that mtCKs is regulated by the same transcription factors from the MyoD and Mef2 family of proteins as CKM [51]. 


\section{Cellular Physiology and Biochemistry}

Cell Physiol Biochem 2014;33:310-320

DOI: 10.1159/000356671

Published onlıne: January 31, 2014

C) 2014 S. Karger AG, Basel

www.karger.com/cpb

Adaptation to chronic hypoxia causes a shift from lipid oxidation to glycolysis [52], which was also reflected in our results. In the present study, we found that HK activity significantly increased in the $\mathrm{LV}$ as well as in the RV under all hypoxic regimens, which is in line with other studies $[53,54]$. This can be related to an increased expression of HK1 and HK2, which we observed only in the LV. Another possible explanation of enhancing HK activity can lie in the posttranslation modifications mediated by AMP-dependent protein kinase (AMPK) [55] or in changes in the enzyme tertiary structure [56]. AMPK is activated by hypoxic stimuli [57] and, beside of regulating HK2 [58], it also inhibits CKM activity by phosphorylation [59]. In addition, the enhancement of HK activity can be achieved by its greater association with mitochondria. It has been shown that Akt kinase phosphorylates HK2 and stimulates its translocation to the mitochondria [29]. However, this mechanism does not seem to play a role in the stimulation of HK activity in our experimental conditions, because we did not observe any increase in mitochondrial co-localization of HK isoforms after adaptation to hypoxia. Nevertheless, it should be mentioned that the present HK assay allowed us to determine the maximal specific activity of both $\mathrm{HK}$ isoforms independently of the localization of the enzyme molecules. Therefore, the disproportionately smaller increase of HK activity as compared to the higher increase of HK expression in our study may rather indicate the effect of posttranslational modifications than changes in interactions of HK with mitochondria. It seems that the present regimens of chronic normobaric hypoxia, similarly as the ischemic preconditioning, could stabilize the binding of HK with mitochondria. Recently, Pasdois et al. have reported that ischemic preconditioning does not increase the HK2 association with mitochondria but reduces its loss from mitochondrial membrane during prolonged ischemic insult, thereby reducing cytochrome $c$ release, oxidative stress, and probability of permeability transition pore opening [60]. It remains to be determined whether similar effects may contribute to the ischemia-resistant phenotype of chronically hypoxic hearts.

Surprisingly, we found discordant changes in the expression of HK1 and HK2 at mRNA level under hypoxic conditions. HK2 significantly increased whereas HK1 remained unchanged. It has previously been observed that adaptation to hypoxia stabilizes the hypoxia inducible factor 1, which potentiates HK2 transcription [61]. Experiments on Saccharomyces cerevisiae revealed that $\mathrm{HK} 2$ can activate its own transcription and repress transcription of HK1 [62], but this regulatory mechanism has not yet been described in mammalian cells.

Adaptation to hypoxia led to significant right-to-left ventricular differences in the expression of mtCKs and both HK isoforms. While the increased expression was observed in the LV, the RV myocardium remained unaffected. This may be related to the fact that both HK1 and HK2 exhibited higher expression levels in the RV than in the LV already under normoxic conditions [43]. Unlike the LV, the RV is exposed to an increased workload due to hypoxic pulmonary hypertension leading to hypertrophy, which may account for the absence of any up-regulation of these enzymes.

In conclusion, our study has demonstrated the similar effects of three different hypoxic regimens on CK and HK isoforms in the myocardium of adult rats. Up-regulation of mitochondrial CK and HK and their activities may lead to a higher stimulation of the respiratory chain via ADP recycling, which can reduce formation of ROS and thus help to prevent oxidative stress and maintain energy homeostasis during hypoxia. Although we did not find any difference between protective and non-protective phenotype, it cannot be excluded that CK and HK may play a role in the cardioprotective mechanisms induced by chronic hypoxia.

\section{Acknowledgements}

This work was supported by the Charles University Grant Agency (349211), the Ministry of Education of the Czech Republic (MSM0021620858), the Grant Agency of the Academy of Science of the Czech Republic (IAAX01110901 and IAAX01110908), and by the Czech Science Foundation (303/12/1162). 


\section{Cellular Physiology \\ and Biochemistry}

Cell Physiol Biochem 2014;33:310-320

\begin{tabular}{l|l}
\hline DOI: $10.1159 / 000356671$ & (C) 2014 S. Karger AG, Basel
\end{tabular}

www.karger.com/cpb

Waskova-Arnostova et al.: Mitochondrial CK and HK in Hypoxic Heart

\section{Conflict of Interests}

The authors declare that they have no competing interests.

\section{References}

1 Wallimann T, Wyss M, Brdiczka D, Nicolay K, Eppenberger HM: Intracellular compartmentation, structure and function of creatine kinase isoenzymes in tissues with high and fluctuating energy demands: the "phosphocreatine circuit" for cellular energy homeostasis. Biochem J 1992;281:21-40.

-2 Ventura-Clapier R, Veksler V, Hoerter JA: Myofibrillar creatine kinase and cardiac contraction. Mol Cell Biochem 1994;133-134:125-144.

-3 Saks VA, Ventura-Clapier R, Aliev MK: Metabolic control and metabolic capacity: two aspects of creatine kinase functioning in the cells. Biochim Biophys Acta 1996;1274:81-88.

4 Schlattner U, Tokarska-Schlattner M, Wallimann T: Mitochondrial creatine kinase in human health and disease. Biochim Biophys Acta 2006;1762:164-180.

5 Kenyon GL, Reed GH: Creatine kinase: structure-activity relationships. Adv Enzymol Relat Areas Mol Biol 1983;54:367-426.

6 Wallimann T, Schlösser T, Eppenberger HM: Function of M-line-bound creatine kinase as intramyofibrillar ATP regenerator at the receiving end of the phosphorylcreatine shuttle in muscle. J Biol Chem 1984;259:5238-5246.

-7 Zurmanova J, Difato F, Malacova D, Mejsnar J, Stefl B, Zahradnik I: Creatine kinase binds more firmly to the M-band of rabbit skeletal muscle myofibrils in the presence of its substrates. Mol Cell Biochem 2007;305:55-61.

8 Newsholme EA, Zammit VA, Crabtree B: The role of glucose and glycogen as fuels for muscle. Biochem Soc Trans 1978;6:512-520.

-9 Smith SH, Kramer MF, Reis I, Bishop SP, Ingwall JS: Regional changes in creatine kinase and myocyte size in hypertensive and nonhypertensive cardiac hypertrophy. Circ Res 1990;67:1334-1344.

10 Ingwall JS: The hypertrophied myocardium accumulates the MB-creatine kinase isozyme. Eur Heart J 1984;5 Suppl F:129-139.

11 Pauletto P, Nascimben L, Piccolo D, Secchiero S, Vescovo G, Scannapieco G, Dalla Libera L, Carraro U, Pessina AC, Dal Palù C: Ventricular myosin and creatine-kinase isoenzymes in hypertensive rats treated with captopril. Hypertension 1989;14:556-562.

12 Fontanet HL, Trask RV, Haas RC, Strauss AW, Abendschein DR, Billadello JJ: Regulation of expression of M, $\mathrm{B}$, and mitochondrial creatine kinase mRNAs in the left ventricle after pressure overload in rats. Circ Res 1991;68:1007-1012.

-13 Pissarek M, Bigard X, Mateo P, Guezennec CY, Hoerter JA: Adaptation of cardiac myosin and creatine kinase to chronic hypoxia: role of anorexia and hypertension. Am J Physiol 1997;272:H1690-1695.

-14 Letout A, Solares-Espinoza M, Mateo P, Koulmann N, Bahi L, Serrurier B, Favier R, Ventura-Clapier R, Bigard $\mathrm{X}$ : Adaptive changes in cardiac myosin heavy chain and creatine kinase isozymic profiles in rats native of altitude. Acta Physiol Scand 2005;184:95-104.

-15 Hornemann T, Stolz M, Wallimann T: Isoenzyme-specific interaction of muscle-type creatine kinase with the sarcomeric M-line is mediated by NH(2)-terminal lysine charge-clamps. J Cell Biol 2000;149:12251234.

-16 Beutner G, Rück A, Riede B, Brdiczka D: Complexes between porin, hexokinase, mitochondrial creatine kinase and adenylate translocator display properties of the permeability transition pore. Implication for regulation of permeability transition by the kinases. Biochim Biophys Acta 1998;1368:7-18.

17 Brdiczka D, Beutner G, Rück A, Dolder M, Wallimann T: The molecular structure of mitochondrial contact sites. Their role in regulation of energy metabolism and permeability transition. Biofactors 1998;8:235242.

18 Saks VA, Kuznetsov AV, Kupriyanov VV, Miceli MV, Jacobus WE: Creatine kinase of rat heart mitochondria. The demonstration of functional coupling to oxidative phosphorylation in an inner membrane-matrix preparation. J Biol Chem 1985;260:7757-7764.

19 Kay L, Nicolay K, Wieringa B, Saks V, Wallimann T: Direct evidence for the control of mitochondrial respiration by mitochondrial creatine kinase in oxidative muscle cells in situ. J Biol Chem 2000;275:69376944. 


\section{Cellular Physiology and Biochemistry}

Cell Physiol Biochem 2014;33:310-320

\begin{tabular}{l|l}
\hline DOI: $10.1159 / 000356671$ & (c) 2014 S. Karger AG, Basel
\end{tabular}

Waskova-Arnostova et al.: Mitochondrial CK and HK in Hypoxic Heart

-20 Meyer LE, Machado LB, Santiago APSA, da-Silva WS, De Felice FG, Holub O, Oliveira MF, Galina A: Mitochondrial creatine kinase activity prevents reactive oxygen species generation: antioxidant role of mitochondrial kinase-dependent ADP re-cycling activity. J Biol Chem 2006;281:37361-37371.

21 Dolder M, Wendt S, Wallimann T: Mitochondrial creatine kinase in contact sites: interaction with porin and adenine nucleotide translocase, role in permeability transition and sensitivity to oxidative damage. Biol Signals Recept 2001;10:93-111.

-22 Dolder M, Walzel B, Speer O, Schlattner U, Wallimann T: Inhibition of the mitochondrial permeability transition by creatine kinase substrates. Requirement for microcompartmentation. J Biol Chem 2003;278:17760-17766.

23 Kowaltowski AJ, Castilho RF, Vercesi AE: Mitochondrial permeability transition and oxidative stress. FEBS Lett 2001;495:12-15.

24 Saks V, Kaambre T, Guzun R, Anmann T, Sikk P, Schlattner U, Wallimann T, Aliev M, Vendelin M: The creatine kinase phosphotransfer network: thermodynamic and kinetic considerations, the impact of the mitochondrial outer membrane and modelling approaches. Subcell Biochem 2007;46:27-65.

25 Pastorino JG, Shulga N, Hoek JB: Mitochondrial binding of hexokinase II inhibits Bax-induced cytochrome c release and apoptosis. J Biol Chem 2002;277:7610-7618.

26 Pastorino JG, Hoek JB: Hexokinase II: the integration of energy metabolism and control of apoptosis. Curr Med Chem 2003;10:1535-1551.

27 Azoulay-Zohar H, Israelson A, Abu-Hamad S, Shoshan-Barmatz V: In self-defence: hexokinase promotes voltage-dependent anion channel closure and prevents mitochondria-mediated apoptotic cell death. Biochem J 2004;377:347-355.

28 Majewski N, Nogueira V, Bhaskar P, Coy PE, Skeen JE, Gottlob K, Chandel NS, Thompson CB, Robey RB, Hay $\mathrm{N}$ : Hexokinase-mitochondria interaction mediated by Akt is required to inhibit apoptosis in the presence or absence of Bax and Bak. Mol Cell 2004;16:819-830.

29 Miyamoto S, Murphy AN, Brown JH: Akt mediates mitochondrial protection in cardiomyocytes through phosphorylation of mitochondrial hexokinase-II. Cell Death Differ 2008;15:521-529.

- 30 Gottlob K, Majewski N, Kennedy S, Kandel E, Robey RB, Hay N: Inhibition of early apoptotic events by Akt/ $\mathrm{PKB}$ is dependent on the first committed step of glycolysis and mitochondrial hexokinase. Genes Dev 2001;15:1406-1418.

-31 da-Silva WS, Gómez-Puyou A, de Gómez-Puyou MT, Moreno-Sanchez R, De Felice FG, de Meis L, Oliveira MF, Galina A: Mitochondrial bound hexokinase activity as a preventive antioxidant defense: steady-state ADP formation as a regulatory mechanism of membrane potential and reactive oxygen species generation in mitochondria. J Biol Chem 2004;279:39846-39855.

-32 Aubert-Foucher E, Font B, Gautheron DC: Rabbit heart mitochondrial hexokinase: solubilization and general properties. Arch Biochem Biophys 1984;232:391-399.

-33 Burcelin R, Printz RL, Kande J, Assan R, Granner DK, Girard J: Regulation of glucose transporter and hexokinase II expression in tissues of diabetic rats. Am J Physiol 1993;265:E392-401.

-34 Wilson JE: An introduction to the isoenzymes of mammalian hexokinase types I-III. Biochem Soc Trans 1997;25:103-107.

-35 Wilson JE: Isozymes of mammalian hexokinase: structure, subcellular localization and metabolic function. J Exp Biol 2003;206:2049-2057.

-36 Lawrence GM, Trayer IP: The localization of hexokinase isoenzymes in red and white skeletal muscles of the rat. Histochem J 1985;17:353-371.

- 37 Southworth R, Davey KAB, Warley A, Garlick PB: A reevaluation of the roles of hexokinase I and II in the heart. Am J Physiol Heart Circ Physiol 2007;292:H378-386.

- 38 Ostadal B, Kolar F: Cardiac adaptation to chronic high-altitude hypoxia: beneficial and adverse effects. Respir Physiol Neurobiol 2007;158:224-236.

-39 Essop MF: Cardiac metabolic adaptations in response to chronic hypoxia. J Physiol (Lond) 2007;584:715726.

40 Novel-Chaté V, Mateo P, Saks VA, Hoerter JA, Rossi A: Chronic exposure of rats to hypoxic environment alters the mechanism of energy transfer in myocardium. J Mol Cell Cardiol 1998;30:1295-1303.

-41 Neckár J, Szárszoi O, Koten L, Papousek F, Ost’ádal B, Grover GJ, Kolár F: Effects of mitochondrial K(ATP) modulators on cardioprotection induced by chronic high altitude hypoxia in rats. Cardiovasc Res 2002;55:567-575. 


\section{Cellular Physiology and Biochemistry}

Cell Physiol Biochem 2014;33:310-320

\begin{tabular}{l|l}
\hline DOI: $10.1159 / 000356671$ & (C) 2014 S. Karger AG, Basel
\end{tabular}

Published onlıne: January 31, 2014

www.karger.com/cpb

Waskova-Arnostova et al.: Mitochondrial CK and HK in Hypoxic Heart

-42 Neckář J, Borchert GH, Hloušková P, Míčová P, Nováková O, Novák F, Hroch M, Papoušek F, Oštádal B, Kolář F: Brief Daily Episode of Normoxia Inhibits Cardioprotection Conferred by Chronic Continuous Hypoxia. Role of Oxidative Stress and BKCa Channels. Curr Pharm Des 2013;19:6880-6889.

43 Waskova-Arnostova P, Elsnicova B, Kasparova D, Sebesta O, Novotny J, Neckar J, Kolar F, Zurmanova J: Right-to-left ventricular differences in the expression of mitochondrial hexokinase and phosphorylation of Akt. Cell Physiol Biochem 2013;31:66-79.

-44 Balková P, Hlaváčková M, Milerová M, Neckář J, Kolář F, Novák F, Nováková 0: N-acetylcysteine treatment prevents the up-regulation of MnSOD in chronically hypoxic rat hearts. Physiol Res 2011;60:467-474.

45 Units of Enzyme Activity. Eur J Biochem 1979;97:319-320.

-46 Nouette-Gaulain K, Malgat M, Rocher C, Savineau J-P, Marthan R, Mazat J-P, Sztark F: Time course of differential mitochondrial energy metabolism adaptation to chronic hypoxia in right and left ventricles. Cardiovasc Res 2005;66:132-140.

-47 Wiesner RJ, Hornung TV, Garman JD, Clayton DA, O'Gorman E, Wallimann T: Stimulation of mitochondrial gene expression and proliferation of mitochondria following impairment of cellular energy transfer by inhibition of the phosphocreatine circuit in rat hearts. J Bioenerg Biomembr 1999;31:559-567.

48 Chida K, Tsunenaga M, Kasahara K, Kohno Y, Kuroki T: Regulation of creatine phosphokinase B activity by protein kinase C. Biochem Biophys Res Commun 1990;173:346-350.

-49 Hemmer W, Riesinger I, Wallimann T, Eppenberger HM, Quest AF: Brain-type creatine kinase in photoreceptor cell outer segments: role of a phosphocreatine circuit in outer segment energy metabolism and phototransduction. J Cell Sci 1993;106:671-683.

-50 Quest AF, Soldati T, Hemmer W, Perriard JC, Eppenberger HM, Wallimann T: Phosphorylation of chicken brain-type creatine kinase affects a physiologically important kinetic parameter and gives rise to protein microheterogeneity in vivo. FEBS Lett 1990;269:457-464.

-51 Qin W, Khuchua Z, Cheng J, Boero J, Payne RM, Strauss AW: Molecular characterization of the creatine kinases and some historical perspectives. Mol Cell Biochem 1998;184:153-167.

52 Holden JE, Stone CK, Clark CM, Brown WD, Nickles RJ, Stanley C, Hochachka PW: Enhanced cardiac metabolism of plasma glucose in high-altitude natives: adaptation against chronic hypoxia. J Appl Physiol 1995;79:222-228.

-53 Daneshrad Z, Garcia-Riera MP, Verdys M, Rossi A: Differential responses to chronic hypoxia and dietary restriction of aerobic capacity and enzyme levels in the rat myocardium. Mol Cell Biochem 2000;210:159166.

54 Rumsey WL, Abbott B, Bertelsen D, Mallamaci M, Hagan K, Nelson D, Erecinska M: Adaptation to hypoxia alters energy metabolism in rat heart. Am J Physiol 1999;276:H71-80.

-55 Holmes BF, Kurth-Kraczek EJ, Winder WW: Chronic activation of 5'-AMP-activated protein kinase increases GLUT-4, hexokinase, and glycogen in muscle. J Appl Physiol 1999;87:1990-1995.

-56 Hoggett JG, Kellett GL: Kinetics of the monomer-dimer reaction of yeast hexokinase PI. Biochem J 1992;287:567-572.

57 Mungai PT, Waypa GB, Jairaman A, Prakriya M, Dokic D, Ball MK, Schumacker PT: Hypoxia triggers AMPK activation through reactive oxygen species-mediated activation of calcium release-activated calcium channels. Mol Cell Biol 2011;31:3531-3545.

-58 Stoppani J, Hildebrandt AL, Sakamoto K, Cameron-Smith D, Goodyear LJ, Neufer PD: AMP-activated protein kinase activates transcription of the UCP3 and HKII genes in rat skeletal muscle. Am J Physiol Endocrinol Metab 2002;283:E1239-1248.

-59 Ponticos M, Lu QL, Morgan JE, Hardie DG, Partridge TA, Carling D: Dual regulation of the AMP-activated protein kinase provides a novel mechanism for the control of creatine kinase in skeletal muscle. EMBO J 1998;17:1688-1699.

60 Pasdois P, Parker JE, Halestrap AP: Extent of mitochondrial hexokinase II dissociation during ischemia correlates with mitochondrial cytochrome $\mathrm{c}$ release, reactive oxygen species production, and infarct size on reperfusion. J Am Heart Assoc 2013;2:e005645.

61 Riddle SR, Ahmad A, Ahmad S, Deeb SS, Malkki M, Schneider BK, Allen CB, White CW: Hypoxia induces hexokinase II gene expression in human lung cell line A549. Am J Physiol Lung Cell Mol Physiol 2000;278:L407-416.

62 Rodríguez A, De La Cera T, Herrero P, Moreno F: The hexokinase 2 protein regulates the expression of the GLK1, HXK1 and HXK2 genes of Saccharomyces cerevisiae. Biochem J 2001;355:625-631. 